\title{
Systems behaviour and implications for service-dominant logic
}

Book or Report Section

Accepted Version

Godsiff, P., Maull, R. and Davies, P. (2018) Systems behaviour and implications for service-dominant logic. In: Vargo, S. L. and Lusch, R. F. (eds.) The SAGE Handbook of Service-Dominant Logic. Sage. ISBN 9781526402837 Available at http://centaur.reading.ac.uk/79275/

It is advisable to refer to the publisher's version if you intend to cite from the work. See Guidance on citing.

Publisher: Sage

All outputs in CentAUR are protected by Intellectual Property Rights law, including copyright law. Copyright and IPR is retained by the creators or other copyright holders. Terms and conditions for use of this material are defined in the End User Agreement. 


\section{CentAUR}

Central Archive at the University of Reading

Reading's research outputs online 


\title{
Chapter 2: Systems Behaviour and Implications for Service-Dominant Logic
}

\begin{abstract}
This chapter considers the influence of Systems Thinking - a way of viewing, defining, analysing and intervening in the "real" world (Checkland, 1999) - on the ongoing development of service-dominant logic ( S-D logic). S-D logic explicitly acknowledges the influence of Systems Thinking, alongside Institutional Logic, in its adoption of systems concepts and a holistic service ecosystems approach. This chapter reviews the systems thinking developments of S-D logic which have been influenced by Systems Thinking, and then suggests six exploration avenues for S-D logic based on Systems Thinking approaches.
\end{abstract}

Keywords: Service-dominant logic, systems thinking, service ecosystems, institutional logic

\section{Introduction}

We begin with a brief discussion on the significant maturing of S-D logic since its inception into an axiom-based discipline, approaching a "near theory status" (Vargo and Lusch, 2017). We discuss the influence of Systems Thinking (ST) on these developments, and then explore the development and growth of ST, in particular the way in which learnings from empirical work and practical interventions and other disciplines have stimulated this growth. We then suggest further ways in which ST can contribute to the ongoing maturing of S-D logic, and how the lessons learnt from the ST "journey" could inform this. We close with suggested conceptual and empirical research themes and areas for further exploration based on ST and S-D logic.

\section{Developments in service-dominant logic}


S-D logic has developed rapidly since its original articulation (Vargo and Lusch, 2004) both through internal refinement and examination, and cross-fertilisation from other disciplines, most notably Institutional Logic and ST. An original eight foundational premises have been extended into 11 premises, five of which are now held to be axioms. The initial set of four axioms covered value creation through service and resource integration: service is the fundamental basis of exchange; value is co-created by multiple actors, always including the beneficiary; all social and economic actors are resource integrators; value is always uniquely and phenomenologically determined by the beneficiary (Vargo and Lusch, 2004).

Refinement and growth of S-D logic have come from a process of "zooming out" to give a wider, more dynamic and "holistic" perspective (Vargo and Lusch, 2016), the embracing of ecosystems and dynamic systems thinking rather than a static network approach, and crossfertilisation from Institutional Logic, providing a theoretical underpinning for the mechanisms. This has resulted in the addition of a new foundational premise (FP11), constituting a fifth axiom, in 2016 to address the need to better understand the means of control and co-ordination within the service ecosystem, namely: value co-creation is coordinated through actor-generated institutions and institutional arrangements (Vargo and Lusch, 2016).

For the sake of completeness and convenience, we set out here in Table 3.1 the 11 foundational premises of S-D logic based on Vargo and Lusch $(2004,2008,2016)$ with the date of origination and subsequent update.

<insert Table 3.1>

Vargo and Lusch (2017) identify four key shifts in perspective in the S-D logic approach to the understanding of markets and marketing. These are from "parts to the whole" (where due to systemic emergent properties a reductionist approach is insufficient); from objects to relationships (usually dynamic and adapting); from structure to processes (which create and influence the structures within which they operate); and from measuring to mapping (identifying recurring 
patterns and emerging properties). These and other developments would be clearly recognisable to systems thinkers and analysts, as many of the key influences on its development can be located in the broad area tenets concepts recognised as ST.

A further benefit of the holistic "zooming out" approach to S-D logic researchers has been to move beyond organisations (producers and consumers) with purely dyadic relations, through static networks to a more holistic actor-to-actor orientation - such that potential underpinnings of a theory of the market begin to emerge (Vargo and Lusch, 2016).

Changing the viewpoint of participants (producers and consumers) to "actors" (those responsible for asset integration and service exchange, and engaged in jointly benefiting each other in dynamic contextual value-creating networks), leads to the realisation that roles are not pre-determined (Vargo and Lusch, 2016) and are more fluid and creative than originally envisaged. S-D logic recognises that dynamic networks - "service ecosystems" - involved in value creation (Vargo and Lusch, 2016) need institutions and institutional frameworks to create and sustain themselves. These institutions (norms, rules practices meanings and symbols; Baron et al, 2017) and frameworks operate within forms identified at three analytic levels of aggregation, typified as macro (societal structures), meso (industry and community) and micro (actors and predominantly dyadic relationships), whose behaviours mutually influence each other(Vargo and Lusch, 2016)

Systems thinking has had considerable influence on service research and indeed, this has always been acknowledged ( $\mathrm{Ng}$ and Maull, 2009). Much of service research uses words such as "complex", "system" and "relationships" in its formation of typologies. So we now turn to systems thinking to explore the origins of these ideas and their underlying philosophy.

A key influence on the development of S-D logic has been the parallel establishment of service science in a symbiotic relationship. Evidence of this mutual influencing is this definitional statement, which is inherently relational and holistic:

"Service science is emerging as the study of value co-creation phenomena in a globally integrated and connected world, which has 
the potential to become significantly smarter and more sustainable. In a service world, diverse entities create, abandon, utilize, ignore, configure, reconfigure, specialize, integrate, protect, and share resources and relationships to co-create benefits with and for each other, both as individuals and collectives, both for the short-term and the long-term." (Spohrer (2009), in Ng and Maull, 2009)

The multidisciplinary aspect is also immediately apparent: "service science is an integrative discipline of engineering, technological and social sciences (including business and law) for the purpose of value co-creation with customers, much like medicine is an integrative discipline of physical and biological sciences for the purpose of healing (Ng and Maull, 2009).

For service science, service takes place within service system, which according to Spohrer, Maglio, Bailey and Gruhl (2007) can be defined as a "value co-production configuration of people, technology, other internal and external service systems and shared information such as language, processes, metrics,prices, policies and laws". This is insightful, but as evidence of the ongoing growth in understanding of S-D logic the concept of "co-creation" is required for all of value creation, while co-production is optional (Vargo and Lusch, 2016).

A service system exists to support the value co-creation process. This dynamic configuration of people, technology and organisations emphasises that in a service system, the "whole" system is the primary unit of analysis and interactions between the components of the system (the employees, customers, technologies and other resources) are just as important as the components themselves within the system that should be configured for effective as well as efficient cocreation of value between actors, such as the customer ( $\mathrm{Ng}$, Maull and Yip, 2009). The more complex the service system, the more important become the relationships amongst the components comprising employees and customers, materials and equipment information and technologies, for as argued by Vargo and Lusch (2008) "all social and economic actors are resource integrators" (Ng et al, 2009).

From service system can be developed the underpinnings of a service ecosystem. An ecosystem 
may be considered to be a self-regulating and self-reinforcing system within its environment, more or less complete within itself. The term was developed by ecologists seeking to understand how living organisms reacted within their environment in natural systems, and move away from more limited views. In this it retraced the steps of early systems thinkers who were influenced by biology (Von Bertalanffy, 1950, 1968) and moved away from mechanistic descriptions. The term 'ecosystem' has been expanded from its naturalistic origins to include human activity systems (Checkland, 1999), which may be deemed to have clearer stronger boundaries and relationships than natural systems. There is a a growing understanding within the S-D logic and other communities that "economic (and other social)networks tend to be self-governed, selfadjusting service ecosystems engaged in value cocreation at various levels of aggregation" (Vargo and Lusch, 2016, p6). However, it must be stressed that the S-D logic concept of 'levels' is conceptual and perspective-driven, rather than being firm boundaries.

From the S-D logic perspective, the social and economic actors of a service ecosystem are held together by a trinity of resources: competences, relationships, and information. Ecosystems are defined as "relatively self-contained, self-adjusting system of resource-integrating actors connected by shared institutional logic and mutual value creation through service exchange" (Lusch and Vargo, 2014). These actors are dynamic in formulation (Ng, Maull and Smith, 2011) and behaviour, coming together to solve problems (Vargo and Akaka, 2009).

Institutions (broadly; rules, assumptions and practices and the sphere in which they operate, such as market and community) and their frameworks provide context in which value can be cocreated through its processes. Institutions take on a key role in S-D logic: "Thus, it is a narrative of cooperation and coordination in ecosystems, as well as the reconciliation of conflict between them" operating within the intsitutions and their frameworks. (Vargo and Lusch, 2016, p17) . There is a need for a method which maintains both the structural flexibility and integrity of the service ecosystem and to manage the potential conflicts between the two. However, the structures or institutions that guide the interaction within a particular system are often composed of multiple viewpoints, a key ST concept (Checkland, 1999). Sewell (1992) draws on the work of Giddens (1984) to discuss the multiplicity of structures in systems with the capacity for change. Sewell (1992, p. 16) argues that, as practices are enacted, multiple structures form "which exist at 
different levels, operate in different modalities, and are themselves based on widely varying types and quantities of resources."

There is a need to develop and maintain a shared worldview or weltenschauung (Checkland, 1999) among this set of potentially cognitively distant actors. The objective of such configurations is to ensure that the overall system (solution) offers the best value-in-use for the user in a particular context. Such regulating "institutions" may be considered as "...rules, norms, meanings, symbols, practices and similar aides to collaboration", and institutional arrangements are "interdependent assemblages of institutions" (Vargo and Lusch, 2016, p. 6). Within the discipline of organisational studies, "institutionalization involves the processes by which social processes, obligation or actualities come to take on rulelike status in social thought and action" (Scott 1987, p. 496).

This is a viewpoint that can further our understanding of the processes and interactions of the actors within the service ecosystem, and moves us beyond a simple representation. This change of viewpoint allows S-D logic, using an ST approach employing the twin concepts of hierarchy and control (Checkland 1999), to include as well as the processes and relationships, the emergence of three levels macro, meso, and micro with interactions between and affecting each level (Akaka and Vargo 2014; Fisk et al. 2016; Witell et al. 2015). Boundaries may be deemed to exist between levels (vertically eg micro, meso, macro) and also to define the extent of the system in focus (spatially and temporally- ie an ecosystem has wider boundaries than a subsystem).

S-D logic draws a new gestalt, a new way of analysing and understanding economic markets, in which a new way of seeing informs our understanding of our intended actions. There is no doubt that S-D logic will continue to develop as it reaches out to other disciplines and continues to explore the disciplines by which it has already been influenced.

\section{Systems thinking}

Systems thinking has a long academic tradition dating back to the open systems concepts of von Bertalanffy (1968) and the control systems work of Wiener (1948) and developed as a reaction to 
"reductionist" approaches. ST was developed by thinkers influenced by the sciences of biology and adaptation, and the vitality and "wholeness" of life, leading some to suggest the word "holon" as a better descriptor than system (Checkland, 1999). The scientific reductionist method seeks the simplest models and predictability through theories and laws of natural systems. However this method needs the simplifying assumptions of (1) weak connections and relationships between the parts; (2) that the parts can be summed back to the whole; and (3) that optimising each part will optimise the whole and does not hold in human activity systems which tend to be complex and open (Ng and Maull, 2009). ST based on holism and the concepts of emergence and hierarchies, was considered to be a realistic counter-action to reductionism and the scientific method when natural, social and managerial sciences were confronted with complex phenomena (Kirk, 1995). ST employs general concepts such as viewpoint, boundaries, feedback, mechanisms, hierarchy, control, purpose, viability, transformation, information, and adaptation; all important factors in determining how systems behave and function. Systems are considered to exist in a series of levels in a hierarchy where the emergent (unexpected or non-predictable) properties or behaviour apparent at a higher level cannot be explained by understanding processes and behaviours at the lower level. This is not so much the whole is greater than the sum of parts, but more the whole is different than the sum of the parts (Goldstein, 1999).

Open systems exchange information and matter with their environment. Closed systems tend to be deterministic and hence optimisable, whereas open systems are more complex and dynamic. ST claims that open systems, of which social (human activity) systems are an example, have identifiable and common behaviours or qualities (Katz and Khan, 1966). By "importing energy" from their environment, or through the energy created by others in a mutually beneficial arrangement (effectively actors in the system), they can achieve a "transformation" and an "output". This takes place in a series of "cycles of (inter-related, structured) events" which cause the system and its structures to becomemore viable and organised (through a process of "negative entropy"). The structure and behaviour becomes formed through processes of "information input, negative feedback, and coding" which promote stability and sense making. Such systems then experience tension between a "steady state and dynamic homeostasis" and adaptation and growth through reacting to disturbances leading to differentiation, elaboration and increasing 
specialisation but attaining the "equifinality" of a final state reached through different paths and starting conditions (Katz and Khan, 1966).

\section{Emergence}

A key aspect of ST is the concept of emergence, which refers to properties of the whole (which in ST are described as emergent) arising from the interaction of several lower level elements or variables. A classic case of an emergent property is the wetness of water. The property "wetness" is not found in either of the elements hydrogen or oxygen, but only occurs when they interact in the form $\mathrm{H}_{2} \mathrm{O}$. The property of harmony in a group of musicians is not found in the component parts, eg. the vocalist and guitar, but only occurs when they interact. Other frequently-used examples include hurricanes $\S$ traffic jams and markets. The key here is to focus on the interaction between the elements and not on the elements themselves: it is from the dynamic interaction and synergy between the elements that emergent properties arise. Synergy is the term to describe the interaction of the parts that lead to emergent properties.

Human activity systems, such as markets or society, too have these features. If we assume for example, that actors in a market come together for the exchange of service to aid resource integration, we can use the term 'synergy' to describe people working together and from this cooperation, properties such as a community or a church emerges. Synergy is more than simply an economy of scale: it arises from the interaction of elements that are different from one another. This difference is important: if the elements are the same then exchanges between them become stale and the system runs down and suffers from entropy. To avoid entropy, the system has to refresh itself through an importation of energy (information or order) from the environment outside, a notion which resonates with the work of Von Bertalanffy (1950) and Katz and Kahn's (1966) on open systems.

Explaining synergy and emergent properties (rather than just describing them) in a logical way is challenging, in respect of identifying what new laws of behaviour are not derivable from the laws operating at lower levels (Audi, 1999) What we are observing in these complex systems is causal 
chains where the effect of one element on a second element returns to influence the original event, perhaps directly or through some intermediate event with either positive or negative feedback. In human activity and other ecosystems it is difficult to point to one-way causality, and influence can work upwards or downwards between the identified levels.

A fundamental principle is that emergent properties are essentially unpredictable - there is a sense of novelty in properties or behaviours (Henle, 1942). A commonly-used definition of emergence is that it cannot be predicted (otherwise it would be deterministic) and is subjectively surprising. Emergence occurs when identifying the parts of the system - and the laws of behaviour applicable to them - tell you little about how it will behave. Emergence is very hard to predict because of the number of elements that interact to produce the property. Seen from one angle it is a combinatorial problem: identifying all the potential outcomes with many millions of interacting elements (all the potential states of the system) is challenging (the number of interactions increases exponentially with the number of actors), and if one considers also the non-linear relationships and multiple feedback loops, the results are impossible to predict.

In order to explain rather than describe the emergent qualities and behaviours in systems such as markets, the laws and variables at the lower levels and the system and the levels themselves need to be specified a priori, ie. identify laws governing lower levels and then look for novelty (Audi 1999, Henle, 1942) to isolate the emergent behaviours. It is possible that the current foundational premises of S-D logic may not be sufficient to fully specify these laws, so empirical work would need to be done within an exploratory framework of levels and laws informed by the foundational premises as well as Institutional Logic.

In the same way that S-D logic has grown and developed through a mixture of introspection and reaching out to other disciplines in its progress towards theory building, so did ST undergo a similar branching out and maturing. By embracing its core principles of widening boundaries and expanding viewpoints, it was able to absorb and use new technical advances (e.g. computing in case of systems dynamics), new mathematical theories and applications (e.g. complexity and chaos theory) and philosophical approaches (e.g. critical realism and post modernism) to its advantage. In addition there was a reaction to practical experience. As problems and obvious failures were 
faced in the implementation of ST approaches in the real world, for example when the results of interventions from the original "hard" and more functionalist approaches were not as expected, (Jackson, 2009), ST was able to respond, with certain strands becoming more interpretive or even taking more extreme positions - such as post modernism (Taket and White, 1993) - in their ontology and epistemology. As a result, ST branched into a number of different approaches, but retained the same adherence to its principal concepts.

Four main phases of ST development have been identified. Jackson (2009) typifies these as the paradigms of functionalist hard ST based on (1) optimisation and efficiency (using the techniques of inter alia, Operations Research, Systems Analysis and Systems Dynamics); (2) exploring purpose and seeking effectiveness (based on situation improving methodologies such as Soft Systems Methodology, Organisational Cybernetics and the Viable Systems Model, and based on theoretical influences such as General Systems Theory and Cybernetics, Appreciative Systems, Socio Technical Systems); (3) critical systems thinking based on empowering methodologies (critical system heuristics and team syntegrity); and finally (4) multi-paradigmatic approaches, (in which methods are combined but used strictly within their own epistemology and ontology) (Jackson, 2009).

These movements through time may be broadly interpreted as changes in the ST approach to social systems. Broadly this can be seen as movements from reductionism through a combinatorial view based on design and construction, (where a system is constructed as a combination of parts and as a part of higher systems (elements and environment) to an even broader integrative view moving outwards from the system under study to systemic wholes This can be neatly encapsulated as the researchers' understanding and focus moving from causality through pragmatism to finality (Muller-Merbach, 1994). 
The various streams of ST differ in how they consider complexity and behaviour, as described by Jackson (2003) Functionalist "Hard” systems thinkers adopt objective-based problem solving, hypothesis testing using models, and treat people as components, not actors. Systems Dynamics allows for a more structuralist approach, using systems concepts to create dynamic mathematical models. The viable systems model (VSM) also adopts a structuralist approach but investigates aspects required for viability / sustainability searching for adaptive goal seeking and environmental relationships. VSM views organisations as organisms with a "brain" and a clear identity, possessing achievable purposes, autonomy, employing the techniques of control and cohesion, laws and negotiation inside a systemic architecture. Complexity theorists meanwhile work at the edge of chaos, and creativity, trying to understand "self organisation", examining an ability to prosper, in a dynamic and unpredictable environment. The more interpretive and pluralistic approaches take differing views on "complexity", seeing it as an issue with the participants (such as their perceptions, values and beliefs, the need for consensus or the presence of conflict and coercion), rather than a description of the behaviour of the system (Jackson, 2003)

An example of an early sociological response to open systems and their need for equilibrium is based on work by Emery and Trist (1960) who developed the concept of "Socio-Technical Systems". The operational work system was a combination of human and technical, which included both social and psychological aspects, including the processes and practices of the "work" which linked to the technology being applied; this combination underpinned systems behaviour. This combination of social and technical is now more likely to be social and digital, leading to the extended concept of socio-digital (Wakenshaw et al, 2014; Sun Lim and Ling Tan, 2003), and can be exhibited in the service ecosystem of the internet.

\section{Systems thinking revisited}

Earlier, we presented the current state of S-D logic in how it has been influenced in its journey towards building a theory of the market through ST approaches. This was followed by a review of these approaches. In this section, we revisit systems thinking to illustrate the similarity of its 
development path with S-D logic, and then we propose six avenues of exploration for service ecosystem researchers that can aid the development of S-D logic theory building and research using ST approaches.

Similar development paths between ST and S-D logic

ST changed as a result of the failure of traditional reductionist approaches in the real world and the influence of new tools and techniques in logical and technical computation computers, and new philosophies. This is in much the same way S-D logic originated from dissatisfaction with marketing's focus on a goods-dominant logic based around neo-classical economics and an extremely limited role for the customer. It drew on learning and concepts from ST and Institutional Logic. ST is an integrative methodology and inherently multi-disciplinary in its application. Both S-D logic and ST exhibit clear evidence of an ability and passion to learn and absorb from other disciplines.

The gestalt change stimulated by General System Theory and ST from "parts to whole" is a significant step in moving beyond the axioms and foundational principles of S-D logic. This has opened up new opportunities for S-D logic, with the new "lens" providing the ability to "see" the whole not parts, and "think" in terms of a dynamic reality with emerging complexity, relationships, processes and patterns. Vargo et al (2017) identify the key challenges for future research as the emergence of markets through the variety of relationships and feedback, and their properties, their behaviour, their growth and stability or otherwise, and how innovation can bring forward new markets and relationships. The positioning of theses broad research areas with regard to these systems concepts that have influenced the development of S-D Logic are set out below in Table 3.2 which is drawn from Vargo et al (2017).

In considering the "framing" concepts of purpose viewpoint and boundaries, it is important to realise that these apply equally to researchers as they do to the "system" under analysis. In choosing to move forward, one choice is between "harder" approaches (problem solving) and "softer" (situation understanding and improving) techniques, though obviously such divisions can 
be blurred. The restrictive and reductionist nature of "hard" techniques make them less suitable for analysis and theory building in social systems and service ecosystems.

Appropriate extant and newly developing techniques exist to address the 10 research themes and questions set up by Vargo et al (2017), as presented in Table 3.2. The behaviour of systems (Forrester 1968, 1997) and their emergent properties as hierarchies develop from their processes can be accessed through a mixture of systems dynamics, and their development into archetypes (Senge 1990 and the expansion of cybernetics and stability and change into Beer's viable system model (Beer, 1984), elaborated in the Viable Systems Approach (Barile, Saviano, Iandolo and Calabrese, 2012). A newly emerging approach of Panarchy, (Gunderson 2001) and exploration of hierarchy within ecosystems is another avenue. These approaches can also address the areas of mapping patterns, relationships and feedback in markets. Other new ways of accessing and understanding markets and their growth empirically with a view to their better management are provided by Transformative Service Research (Baron et al, 2017).

<Insert Table 3.2>

\section{Seven Explorations using Systems Thinking Approaches for S-D logic}

\section{Exploration 1: Adopting a Systems Dynamics methodology}

Systems dynamics was established as a methodology examining the effects of dynamic timedependent behaviour in organisations and supply chains (including the customer) by Forrester (1968). This work was extended by Meadows and Meadows (1973) and popularised by Senge $(1990,2014)$ in his work on the "fifth discipline" - this being ST (used as an intervention to create learning organisations). 
The broad aim of Systems Dynamics is the mathematical modelling of the behaviour of an endogenous system using the concepts and structures of information, stocks, flows, non-linear feedback loops, time delays and control in order to predict cause-effect behaviour and move the system from its observed position back towards its goal. Systems Dynamics models can become very complex in fully capturing the reality of a system assumed to be "out there", though insights can be obtained from relative simple descriptions.

\section{Exploration 2: Understanding Interventions}

Intervening in a system, especially a complex system which is able to change and adapt, requires an understanding of the levels at which interventions can be made and at which they are most effective. These levels were described by Meadows (1997) who suggested 12 levels at which an intervention could be made to a dynamic adaptive system in four broad areas:

1. The operating mechanics of the system: These are the "hard" values underlying the mechanics of a Systems Dynamics model, describing the behaviour of the system such as constants, stock sizes relative to flows, timing delays and rates of change, and strength and nature of feedback loops.

2. The information flows and rules: For instance who has access to what information in what structure, under what rules, incentives and punishments does it operate.

3. The goals and structure of the system: How can the goals be added to or changed, how does the system self organise?)

4. The mind-set or paradigm by which the system operates, and which gives rise to and governs the lower levels.

According to Meadows (1997), changes made or attempted higher in the system "hierarchy" are harder to design and implement but become increasingly effective. So changing the behaviour of a system may be achieved by altering some of the strengths of feedback loops and delays. Changing the information flows and rules (which effectively form part of the institutions of the system) may require more intense activity. Changing the goals and structure, 
or paradigm of a system, (eg as in our case study of challenging current norms of data ownership or value in the internet, or changing the mind-set of marketing and other researchers and practitioners to one of S-D logic), though extremely difficult, has a bigger and longer-lasting impact. Meadows (1997) describes it as the "power to transcend paradigms".

\section{Exploration 3: Establishing Archetypes}

Senge (1990) created a variety of archetypes of systems behaviour based on the tools and techniques of Systems Dynamics. The principles of Systems Dynamics (non-linear positive and negative feedback, and time delays affecting the currency of actions and decisions, endogenous systems) can be used to create two different loops or "circles of causality" (balancing or moving towards a desired goal and reinforcing moving away from a desired goal). Senge (1990) used these in a variety of combinations to create "archetypes" depicted as causal loop diagrams (pictograms) with stories representing common real situations faced by organisations within their environment, to enable organisational learning and act as precursors to interventions in problematic situations. Immediately relevant archetype examples are the "tragedy of the commons" (where competition leads to resource depletion reducing benefit to all), "shifting the burden" (where structures and activities end up treating symptoms rather than causes and move away from the desired goal), "success to the successful" (where resources become concentrated in one actor), "limits to success" (a limiting condition slows growth), and "accidental adversaries" (competition unwittingly leads to reduced local and global performance). Research is needed on the applicability of the existing archetypes and then using this technique to define and examine other potential market archetypes.

\section{Exploration 4: Using Soft-systems methodologies}

Systems thinking can be defined as the "use of systems ideas when facing a problematic situation"

(Paucar-Caceres, 2003, p65) and is seen as the basis for efficient intervention in systems. Not all systems are well-defined or well-structured and thus accessible to approaches based on Systems 
Dynamic analysis. Most complex social systems exist in ill-structured problem situations, or "messes" (Churchman, 1967), which are not susceptible to mathematical modelling. This is partly because of the need for the model to contain all the relevant variables, and partly due to Human Activity Systems containing people, all of whom do not share the same viewpoint about either the problem or the range of solutions, nor have similar power to propose and implement solutions. Such situations have often been referred to as wicked problems (Rittel and Webber, 1973). Wicked problems have a set of perceived qualities such as indeterminacy, no stopping rule, long lead times, and are of such a size and one-off nature that makes experimentation impossible; as such they are unsuitable for reductionist techniques. A different philosophical approach to understanding and intervening in systems was derived from the work of Checkland (1999).

Checkland and Scholes (1990) suggest that an effective way to intervene is to introduce a methodology that emphasises the plurality of viewpoints that exist among participants in a “system". Soft Systems Methodology (SSM) involves making a model of "constructed abstracts", of the world, and testing interventions in the model to learn about the perceived world, prior to taking solutions back to the real world. SSM takes as given that no objective and complete account of a problem situation can be provided, and creates a variety of models based on these different viewpoints, for discussion. It makes use of the concept of CATWOE - that systems can be considered as comprising the following elements: Customers, (the beneficiaries or "victims" of the system) of an Actor-operated Transformation process, within a "Weltanschauung" (worldview) which makes meaningful sense of $\mathbf{T}$ (which will differ between participants); the system of $\mathbf{T}$ being “owned" by Owners who have the power to prevent $\mathbf{T}$ from happening, within an Environment, which is outside the system and taken as given. It often uses pictograms such as rich pictures to share mental models among participants.

The work of soft systems dynamics seeks to use the strengths of Systems Dynamics and SSM to address the weaknesses perceived in both to produce a multi-paradigmatic approach combining hard and soft approaches. Soft systems dynamics methodology or SSDM (Rodriguez-Ulloa and Paucar-Caceres, 2005) has been used in real-world situations to enhance both the problem identification and problem-solving steps, ensuring that the existence of multiple viewpoints or Weltanschauungs in a social system is both recognised in identifying the problem and used in 
providing solutions. The ongoing resource integration reassembling and concomitant co-creation of value - within service ecosystems where the viewpoints of actors may not align - calls out for an approach that is inherently phenomenologically-based, dynamic and able to embrace multidisciplinarity.

\section{Exploration 5: Using Viable Systems Approach}

The Viable Systems Approach, (Barile, Pels, Polese and Saviano, 2012) is an elaboration of the cybernetic theories and practices of the viable systems model (VSM) work carried out by Stafford Beer (1984) and subsequently by Raul Espejo (Espejo, 1999). The keys to systems viability according to the cybernetic school are the twin pillars of communications and control (Wiener, 1961). Beer's description of the viable systems model is based on the need to appropriately match and regulate incoming variety to a system (Ashby, 1969) Ashby's law of requisite variety states that to remain viable, the organisation or system must be able to respond to and adapt in the face of environmental disturbances. Beer (1984) posited that to fulfil these viability requirements and

for continued successful operation, a system needed to comprise five functional activities or subsystems, namely: policy, intelligence, operational control, co-ordination and implementation; and that each of these activities should be embedded in all structural levels. Of particular importance was the quality of the information channels and flows between these subsystems in the system ie. the linkages between the functional activities/levels. These linkages, enabling the information flows along relationships, may be considered to be "conversations grounding shared constructs in a common reality" (Espejo, 1994). These "conversations" may be considered to be analogous to the "institutions" within a service ecosystem. Originally, VSM was explicitly linked to prescriptive descriptions of organisations and enterprises with a clear identity and purpose), rather than a more actor-to-actor approach, implying control from the top of the hierarchy (Beer, 1981). 
VSA has attempted to further develop and extend what we might call a softer, more interpretivist approach. Following Espejo (1999) and his view that a viable system was a collective, producing emergent meanings.

VSA is an approach built on overcoming the reductionist limitations in the examination of social systems (Barile et al, 2014) by using an "updated perspective" of the VSA approach, with a focus on "governing decisions" rather than more mundane operational considerations (Golinelli, Barile, Saviano and Polese, 2012) and expanding and blurring boundaries beyond the enterprise. The "acting" of systems with sub and supra systems creates "institutions" (Barile et al, 2014). and VSA provides a way to think about systemic behaviour through consonance (the alignment of internal processes) and resonance (the emergence of strong external relationships through internal consonance. Interesting applications of combining VSA (which holds reductionist and systemic approaches in a creative tension) and S-D logic perspectives can be found in developing more inclusive business models(Pels et al, 2014), and sustainable spatial and temporal business behaviour (Barile et al, 2014).

\section{Exploration 6: Investigating "panarchy"}

Another useful avenue that service ecosystem researchers can explore is the recent development of "panarchy" (Gunderson, 1995) within ecosystems. This is a body of work originating in ecology and ecosystems management that further examines the notion that global governance is not necessarily hierarchical. Panarchy is a conceptual model that describes the ways in which complex systems of people and nature are dynamically organised and structured across scales of space and time (Gunderson, 2001; Holling, 2001, 2005). It employs twin spatial and temporal scales to create a model of the spatial and temporal dynamic organisation and structuring of natural and human complex systems.

Panarchy developed as an ecosytems approach to study and explain ecosystems behaviour with an emphasis on "hierarchical structuring" (Allen et al 2014), but where "control" can be "bottom "up as well as "top down". The approach views ecosystems as operating within a "nested set of adaptive cycles operating at discrete ranges of scales" (Allen et al. 2014 referencing Holling and 
Gunderson, 2002) At each level, defined roughly by scale of participant, there are observable structural patterns driving behaviour. This gives the behaviour of the complex ecosystem a relatively stable quality, where their variability stays within the systems' domain of attraction. Thus this approach offers reasonably predictable dynamics and the relatively constant provision of ecosystem goods and services. An advantage of this meta analysis approach would be that it is not limited to the three traditional hierarchy levels of macro, meso and micro (high, medium, and low), and may enable a more better granularity of understanding in actor-to-actor relationships. Its initial areas of study using this perspective have been natural ecosystems, sociological systems and governance systems. It has identified that ecosystems and social systems share the qualities of top down and bottom up controls and influences, exist at a range of scales and benefit from non linear dynamics. The approach is currently being employed in the study of urban systems and firm sizes and can derive testable hypotheseses showing the benefits of empirical research (Allen et al, 2014).

\section{Conclusion}

Baron et al (2017) offer an interesting case study in Transformative Service Research based on ST and institutional logic. The case study, involving applied research in a food supply ecosystem, demonstrated that understanding and challenging the systems' institutions can result in ecosystem innovation, through the different viewpoints of the participants, and their impact on the range of the institutions within the ecosystem. Baron et al (2017) suggest that this combinatorial approach (S-D logic, Institutional Logic, ST) employing concepts and methodologies from each, represents a useful way forward in understanding innovation in service ecosystems, with sequential steps of actor identification (especially the central actor) and key interactions, seeking out their individual stories. In their empirical work they employed the concept of an Actor Institutions Matrix as "a representation of the current service system design" in which each actor's viewpoint and role in developing each of the institutions (norms, rules, practices, meanings and symbols) is set out, enabling easy comparisons and analysis useful for exploring how challenges to the institutions can result in innovation to move the system towards better performing its main service concept 
(Baron et al, 2017).

There have been further cross-disciplinary work in employing the ST approach and case study methods, particularly in systems where there may be a plurality of viewpoint or coercive relationships that involve combining ST, in particular SSM (Checkland, 1999) and grounded theory to produc e a combined research methodology employing the multiple perspectives of the actors and the researcher (Durant-Law, 2005; Wiesche, Jurisch, Yetton, and Krcmar, 2017) We therefore urge service ecosystem researchers to conduct empirical work based on S-D logic which will inevitably help in building a theory of the market.

There is a need to engage with reality, either through making practical interventions (possibly employing action research methods) or through building mid-range theory (Brodie, Saren and Pels, 2011) with case studies potentially providing the entry point (Baron et al, 2017), possibly building up experience in employing grounded theory and ST together ( Durant-Law, 2005) It should be remembered however that interventions and case studies are essentially reductionist (Baron et al, 2017) and possibly “wicked” (Rittel and Webber, 1973), and multi-paradigmatic applications need to be protected by consistent application of rigorous method (Jackson, 2006). ST approaches based on the developed theory and use of ST have a clear ongoing contribution to make to the evolution of S-D logic by “creating common synergies and research paths (Polese et al, 2017) and embracing "holistic and high level focus as well as reductionist and vertical studies and application" (Barile et al, 2016). There are also ongoing calls for investigation of empirical multi-disciplinary research into digital phenomena ( $\mathrm{Ng}$ et al, 2012).

There is nothing so practical as a good theory (Van De Ven, 1989), whether it is descriptive or transformative (Ng and Wakenshaw, 2017). Hunt (2002) notes that a theory needs a systematic set of statements, contain law like generalisations and to be empirically testable; in addition it needs to be simple and explain a broad range of phenomena within the unit of analysis (Schmenner and Swink, 1998). Having dealt with issues of definitions and domain, a key stage in theory building is "relationships" - answering the 'how' and 'why' questions which enables the when and where questions (Wacker, 1998).

ST is more akin to an applied methodology and way of thinking applicable in many disciplines, 
than a theoretical or theory-based subject or an object of study; hence its often proprietorial nature with its method closely attributable to a person or particular group. The different schools (Jackson, 2003) can be ascribed different metaphors which typify part of their particular worldview. For example, functionalists can be thought of as viewing systems as being analogous to machines, brains or organisms in constant flux and transformation; interpretive view systems as learning political and social cultures. The development of ST is partly the operationalisation of the new insights that have arisen from the respective approaches learning from insights gained during intervention designed to make distinctive and sustainable changes and subsequent introspection. This is not necessarily a fragmentation of a discipline but as much a reflection of the difficulty of practical application in a range of circumstances.

The nature of the service ecosystem and market with respect to the viewpoints of the participants (unitary, pluralistic or coercive) is an area worthy of further exploration, particularly from an ST approach. The maturing of ST has been described as the movement from "where is the problem?", through "what is the problem?", to "who is the problem?" (Jackson 2003) The development of SD logic and examination of service systems may move along similar perspectives of understanding, potentially progressing from "where is the market?", through "what is the market?", to possibly the ultimate question of "who is the market?"

\section{References}

Akaka, M. A., \& Vargo, S. L. (2014). Technology as an operant resource in service (eco) systems. Information Systems and e-Business Management, 12(3), 367-384.

Allen, C. R., Angeler, D. G., Garmestani, A. S., Gunderson, L. H. and Holling, C. S. (2014). Panarchy: theory and application. Ecosystems, 17, 578-589.

Ashby, W. R. (1969). Self Regulation and Requisite Variety. In: EMERY, F. E. (ed.) Systems Thinking. Middlesex: Penguin Books.

Audi, R. (1999). The Cambridge dictionary of philosophy. 
Barile, S., Lusch, R., Reynoso, J., Saviano, M. and Spohrer, J. (2016). Systems, networks, and ecosystems in service research. Journal of Service Management, 27, 652-674.

Barile, S., Pels, J., Polese, F., \& Saviano, M. (2012). An introduction to the viable systems approach and its contribution to marketing.

Barile, S., Saviano, M., Iandolo, F., \& Calabrese, M. (2014). The viable systems approach and its contribution to the analysis of sustainable business behaviors. Systems Research and Behavioral Science, 31(6), 683-695.

Baron, S., Patterson, A., Maull, R. and Warnaby, G. (2017). Feed people first:a service ecosystem perspective on innovative food waste reduction. Journal of Service Research, O, 1094670517738372.

Beer, S. (1981). Brain of the Firm. John Wiley \& Sons.

Beer, S. (1984). The viable system model: its provenance, development, methodology and pathology. Journal of the Operational Research Society, 35, 7-25, 19.

Brodie, R. J., Saren, M., \& Pels, J. (2011). Theorizing about the service dominant logic: The bridging role of middle range theory. Marketing Theory, 11(1), 75-91.

Checkland, P. (1999). Systems Thinking, Systems Practice - A 30 year retrospective, Chichester, England, John Wiley.

Checkland, P. and Scholes, J. (1990). Soft Systems Methodology in action, Chichester, John Wiley \& Sons Ltd.

Churchman, C. W. (1967). Wicked Problem, . Management Science, 4(4), p. 141-142.

Durant-Law, G. (2005). Soft systems methodology and grounded theory combined: a knowledge management research approach. actKM Online Journal of Knowledge Management, 2, 13-23.

Emery, F. and Trist, E. (1960). Socio-technical systems. Management Science Models and Techniques., London, Pergamon.

Espejo, R. (1994). What is systemic thinking?. System Dynamics Review, 10(2-3), 199-212.

Espejo, R. (1999). Aspects of identity, cohesion, citizenship and performance in recursive organisations. Kybernetes, 28( 6/7), pp.640-658, https:// doi.org/10.1108/03684929910282935.

Fisk, R. P. P., Anderson, L., Bowen, D. E., Gruber, T., Ostrom, A., Patrício, L., Reynoso, J. and Sebastiani, R. (2016). Billions of impoverished people deserve to be better served: A call to action for the service research community. Journal of Service Management, 27, 43-55. 
Forrester, J. W. (1968). Industrial dynamics — after the first decade. Management Science, 14, 398-415.

Forrester, J. W. (1994). System dynamics, systems thinking, and soft OR. System dynamics review, 10, 245-256.

Giddens, A. (1984). The constitution of society: Outline of the theory of structuration. Berkeley: $U$ of California $P$.

Goldstein, J. (1999). Emergence as a construct: History and issues. Emergence, 1(1), 49-72

Golinelli, G. M., Barile, S., Saviano, M. and Polese, F. (2012). Perspective shifts in marketing: toward a paradigm change? Service Science, 4, 121-134.

Gunderson, L. H., Light, S. S., \& Holling, C. S. (1995). Lessons from the Everglades. BioScience, 45, S66-S73.

Gunderson, L. H. (2001). Panarchy: understanding transformations in human and natural systems, Island press.

Henle, P. (1942). The status of emergence. The journal of Philosophy, 39(18), 486-493.

Holling, C. S. (2001). Understanding the complexity of economic, ecological, and social systems. Ecosystems, 4, 390-405.

Holling, C. S. (2005). From complex regions to complex worlds. Minn. JL Sci. \& Tech., 7, 1.

Holling, C. S. and Gunderson, L. H. (2002). Panarchy: understanding transformations in human and natural systems, Island Press.

Hunt, S. D. (2002). Foundations of marketing theory: Toward a general theory of marketing, ME Sharpe.

Jackson, M. C. (2003). Systems Thinking,Creative Holism for Managers, Chichester, John Wiley \& Sons.

Jackson, M. C. (2006). Creative holism: A critical systems approach to complex problem situations. Systems Research and Behavioural Science, 23, 647-657.

Jackson, M. C. (2009). Fifty years of systems thinking for management. Journal of the Operational Research Society, 60, s24-s32.

Katz, D. and Khan, R. L. (1966). The Social Psychology of Organisations, New York, Wiley.

Kirk, D. (1995). Hard and soft systems: a common paradigm for operations management? International Journal of Contemporary Hospitality Management, 7(5), 13-16. 
Lusch, R. F., \& Vargo, S. L. (2014). Service-dominant logic: Premises, perspectives, possibilities. Cambridge University Press.

Meadows, D. (1997). Places to intervene in a system. Whole Earth, 91, 78-84..

Meadows, D. H., Meadows, D. L., Randers, J. and Behrens, W. W. (1972). The limits to growth: a report for the culb of rome's project on the predicament of mankind. New American Library.

Meadows, D. L. and Meadows, D. H. (1973). Toward global equilibrium. Collected Papers, Wright-Allen Press, Cambridge (January).

Muller-Merbach, H. (1994). A System of System Approaches. Interfaces, 24(4), 16-25.

Ng, I., Badinelli, R., Polese, F., Nauta, P. D., Löbler, H. and Halliday, S. 2012. SD logic research directions and opportunities: The perspective of systems, complexity and engineering. Marketing Theory, 12, 213-217.

Ng, I. C., \& Maull, R. (2009, July). Embedding the new discipline of service science: A service science research agenda. In Service Operations, Logistics and Informatics, 2009. SOLI'09. IEEE/INFORMS International Conference on (pp. 68-73). IEEE.

Ng, I., Maull, R. and Smith, L. (2011). Embedding the new discipline of service science. The science of service systems. Springer.

Ng, I. C., Maull, R., \& Yip, N. (2009). Outcome-based contracts as a driver for systems thinking and service-dominant logic in service science: Evidence from the defence industry. European Management Journal, 27(6), 377-387.

Ng, I. C., \& Wakenshaw, S. Y. (2017). The Internet-of-Things: Review and research directions. International Journal of Research in Marketing, 34(1), 3-21.

Paucar-Caceres, A. (2003). Measuring the effect of highly cited papers in OR/MS journals: A survery of articles citing the works of Checkland and Jackson. Systems Research and Behavioural Science, 20, 65-79.

Pels, J., Barile, S., Saviano, M., Polese, F., \& Carrubbo, L. (2014). The contribution of VSA and SDL perspectives to strategic thinking in emerging economies. Managing Service Quality, 24(6), 565-591.

Polese, F., Carrubbo, L., Bruni, R., Bruni, R., Maione, G. and Maione, G. (2017). The viable system perspective of actors in eco-systems. The TQM Journal, 29, 783-799. 
Rittel, H. and Webber, M. (1973). Dilemmas in a General Theory of Planning. Policy Sciences, 4, 155-169.

Rodriguez-Ulloa, R. and Paucar-Caceres, A. (2005). Soft system dynamics methodology (SSDM): combining soft systems methodology (SSM) and system dynamics (SD). Systemic Practice and Action Research, 18, 303-334.

Schmenner, R. W., \& Swink, M. L. (1998). On theory in operations management. Journal of operations management, 17(1), 97-113.

Scott, W. R. (1987). The adolescence of institutional theory. Administrative science quarterly, 493-511.

Senge, P. (1990). The fifth discipline: The art and science of the learning organization. New York: Currency Doubleday.

Senge, P. M. (2014). The fifth discipline fieldbook: Strategies and tools for building a learning organization, Crown Business.

Sewell Jr, W. H. (1992). A theory of structure: Duality, agency, and transformation. American journal of sociology, 98, 1-29.

Spohrer, J. (2009). Editorial column-Welcome to our declaration of interdependence. Service Science. Available: http://www.sersci.com/ServiceScience//upload/12273996030.pdf Spohrer, J., Maglio, P. P., Bailey, J. and Gruhl, D. (2007). Steps toward a science of service systems. Computer, 40.

Sun Lim, S. and Ling Tan, Y. (2003). Old people and new media in wired societies: Exploring the socio-digital divide in Singapore. Media Asia, 30, 95-102.

Taket, A. and White, L. (1993). After OR: An Agenda for Postmodernism and Poststructuralism in OR. The Journal of the Operational Research Society, 44, 867-881.

Van De Ven, A. (1989). Nothing is Quite so Practical as a Good Theory. Academy of Management Review, 14, 486-489.

Vargo, S. L. and Akaka, M. A. (2009). Service-dominant logic as a foundation for service science: clarifications. Service Science, 1, 32-41.

Vargo, S. L., Koskela-Huotari, K., Baron, S., Edvardsson, B., Reynoso, J. and Colurcio, M. (2017). A systems perspective on markets-Toward a research agenda. Journal of Business Research. 
Vargo, S. L. and Lusch, R. F. (2008). Service-dominant logic: continuing the evolution. Journal of the Academy of marketing Science, 36, 1-10.

Vargo, S. L. \& Lusch, R. F. (2004). Evolving to a new dominant logic for marketing. Journal of Marketing, 68, pp.1-17.

Vargo, S. L. and Lusch, R. F. (2016). Institutions and axioms: an extension and update of service-dominant logic.(Conceptual/Theoretical Paper)(Report). Journal of the Academy of Marketing Science, 44, 5.

Vargo, S. L. and Lusch, R. F. (2017). Service-dominant logic 2025. International Journal of Research in Marketing, 34, 46-67.

Von Bertalanffy, L. (1950). An Outline of General System Theory. British Journal for the Philosophy of Science, 1, 139-164.

Von Bertalanffy, L. (1968). General System Theory: Foundations, Development, Applications, New York, George Braziller.

Wacker, J. G. (1998). A definition of theory: research guidelines for different theory-building research methods in operations management. Journal of operations management, 16(4), 361385.

Wakenshaw, S. Y., Ng, I. C., Venters, W., Brown, K., Lloyd, A., Speed, C., Rajarajan, M. and Pym, D. (2014). Revisiting technology thinking in service innovations and consumer experiences: an empirical research.

Wiesche, M., Jurisch, M. C., Yetton, P. W., \& Krcmar, H. (2017). Grounded Theory Methodology in Information Systems Research. MIS Quarterly, 41(3), 685-701.

Witell, L., Anderson, L., Brodie, R. J., Colurcio, M., Edvardsson, B., Kristensson, P., ... \& Wallin Andreassen, T. (2015). Exploring dualities of service innovation: implications for service research. Journal of Services Marketing, 29(6/7), 436-441.

Wiener, N. (1948). Cybernetics: Control and communication in the animal and the machine, Wiley New York.

Wiener, N. (1961). Cybernetics or Control and Communication in the Animal and the Machine, MIT press.

Table 3.1: The 11 foundational premises of S-D logic (Vargo and Lusch 2004, 2008, 2016)

\begin{tabular}{l|l|c}
\hline FP 1 & Service is the fundamental basis of exchange (2008) & Axiom
\end{tabular}




\begin{tabular}{|c|l|c|}
\hline FP 2 & Indirect exchange masks the fundamental basis of exchange (2008) & \\
\hline FP 3 & Goods are distribution mechanisms for service provision (2004) & \\
\hline FP 4 & $\begin{array}{l}\text { Operant resources are the fundamental source of strategic benefit } \\
\text { (2016) }\end{array}$ & \\
\hline FP 5 & All economies are service economies (2004) & Axiom \\
\hline FP 6 & $\begin{array}{l}\text { Value is co-created by multiple actors, always including the } \\
\text { beneficiary (2016) }\end{array}$ & $\begin{array}{l}\text { Actors cannot deliver value but can participate in the creation and } \\
\text { offering of value propositions (2016) }\end{array}$ \\
\hline FP 7 & $\begin{array}{l}\text { A service-centred view is inherently beneficiary-oriented and } \\
\text { relational }\end{array}$ & \\
\hline FP and economic actors are resource integrators (2008) & Axiom \\
\hline FP 9 & $\begin{array}{l}\text { All social and } 10 \\
\text { Value is always uniquely and phenomenologically determined by } \\
\text { the beneficiary (2008) }\end{array}$ & Axiom \\
\hline FP 11 & $\begin{array}{l}\text { Value cocreation is coordinated through actor-generated } \\
\text { institutions and institutional arrangements (new in 2016) }\end{array}$ & Axiom \\
\hline
\end{tabular}


Table 3.2: Positioning of broad research areas with regard to these systems concepts that have influenced the development of S-D Logic drawn from Vargo et al (2017).

\begin{tabular}{|c|c|c|}
\hline Perspective shift & Description / Statement & Research Areas \\
\hline $\begin{array}{l}\text { From the parts to the } \\
\text { whole }\end{array}$ & $\begin{array}{l}\text { Complex systems are wholes } \\
\text { whose emerging properties } \\
\text { cannot be reduced to those of } \\
\text { smaller parts. }\end{array}$ & $\begin{array}{l}\text { - How markets as complex } \\
\text { systems (wholes) behave? } \\
\text { - What are the emergent } \\
\text { properties of markets? } \\
\text { - How micro phenomena bring } \\
\text { forth macro phenomena in } \\
\text { markets and vice versa? }\end{array}$ \\
\hline $\begin{array}{l}\text { From objects to } \\
\text { relationships }\end{array}$ & $\begin{array}{l}\text { Objects are seen as networks } \\
\text { of relationships, embedded in } \\
\text { larger networks. }\end{array}$ & $\begin{array}{l}\text { - How do relationships bring } \\
\text { forth markets? } \\
\text { - How the constellations of } \\
\text { relationships are coordinated } \\
\text { within markets? }\end{array}$ \\
\hline $\begin{array}{l}\text { From structures to } \\
\text { processes }\end{array}$ & $\begin{array}{l}\text { All structures are seen as } \\
\text { manifestations } \\
\text { underlying processes }\end{array}$ & $\begin{array}{l}\text { - What are the underlying } \\
\text { processes } \\
\text { markets? } \\
\text { - How markets emerge, evolve } \\
\text { and cease to exist? } \\
\text { - How innovation is related to } \\
\text { market evolution? }\end{array}$ \\
\hline $\begin{array}{l}\text { From measuring to } \\
\text { mapping }\end{array}$ & $\begin{array}{l}\text { Methodologies need to } \\
\text { move toward mapping and } \\
\text { identifying patterns, } \\
\text { because relationships and } \\
\text { processes cannot be } \\
\text { measured in the traditional } \\
\text { sense due to their emerging } \\
\text { properties. }\end{array}$ & $\begin{array}{l}\text { - What are the enduring } \\
\text { patterns of markets } \\
\text { - What kind of feedback } \\
\text { mechanisms characterise } \\
\text { markets? }\end{array}$ \\
\hline
\end{tabular}

